\title{
Hidrofoilli Teknelerde Kullanılan Su Altı Kanat Yapılarındaki Serbest Yüzey Etkileşimlerinin Sınır Elemanları Yöntemi ile İncelenmesi
}

\author{
Yavuz Hakan Özdemir ${ }^{1}$, Taner Çoşgun ${ }^{2 *}$ \\ ${ }^{1}$ Canakkale Onsekiz Mart Üniversitesi, Deniz Teknolojileri Meslek Yüksekokulu, Motorlu Araçlar ve Ulaştırma Teknolojileri Bölümü, Çanakkale, Türkiye (ORCID: \\ 0000-0002-0406-0532)yhozdemir@,comu.edu.tr \\ 2* Yıldız Teknik Üniversitesi, Gemi Inşaatı ve Denizcilik Fakültesi, Gemi İnşaatı ve Gemi Makineleri Mühendisliği Bölümü, İstanbul, Türkiye (ORCID: 0000-0002- \\ 1364-0133)tcosgun@yildiz.edu.tr
}

(İlk Geliş Tarihi 16 Temmuz 2020 ve Kabul Tarihi 4 Kasım 2020)

(DOI: 10.31590/ejosat.768325)

ATIF/REFERENCE: Özdemir, Y.H. \& Çoşgun, T. (2020). Hidrofoilli Teknelerde Kullanılan Su Altı Kanat Yapılarındaki Serbest Yüzey Etkileşimlerinin Sınır Elemanları Yöntemi ile İncelenmesi. Avrupa Bilim ve Teknoloji Dergisi, (20), 572-580.

$\ddot{O ̈ z}$

Hidrofoilli tekneler, ek kaldırma kuvveti oluşturmak amacıyla serbest yüzey altında ilerleyen kanatlar kullanır. Tekne yüzeyinin bir uzantısı olan kanatlar tarafından oluşturulan kaldırma kuvveti, tekneyi yukarı yönde iterek deplasman hacminin -dolayısıyla- direncin azalmasını sağlarlar. Serbest yüzeyin oldukça yakınında çalışan bu tarz kanat yapılarının performansının belirlenmesinde, serbest yüzeyle girecekleri etkileşimlerin de rol oynaması beklenir. Bu çalışmada, su altında ilerleyen iki boyutlu bir NACA 0012 kanat kesitinin performansı ve serbest yüzey etkileşimleri sayısal olarak incelenmiştir. Bu amaçla, serbest yüzeyden bir kort boyu mesafede bulunan kesitli kanat etrafındaki akım, geniş bir Froude sayısı aralığında potansiyel akım temelli iteratif sınır elemanları yöntemi kullanarak modellenmiştir. Kullanılan yöntemin matematiksel ayrıntıları detaylı bir biçimde sunulmuştur. Çalışma sonucunda, serbest yüzey yakınında çalışmanın kanat kesiti üzerinde oluşan kaldırma ve direnç kuvvetlerini önemli ölçüde etkilediği gözlenmiş ve bu kuvvetlerin değişimi Froude sayısına bağlı olarak incelenmiştir. Ayrıca, kanat tarafından serbest yüzey deformasyonları oluşturulduğu belirlenmiş, oluşan dalga genliğinin Froude Sayısına bağlı olarak arttığı görülmüştür.

Anahtar Kelimeler: Sınır elemanları yöntemi, Potansiyel akım, Hesaplamalı akışkanlar dinamiği, NACA0012 kanat, Batmış hidrofoiller, Serbest yüzey, Kaldırma.

\section{Evaluation of Free Surface Interaction of a Submerged Hydrofoil using Boundary Element Method}

\begin{abstract}
Hydrofoil crafts use submerged foils to gain additional lift force. Lift produced by the submerged foils push the hull upwards and let the drag of the body decrease by lowering the displacement. Free surface interactions effects the performance of the foils, which are travelling close to the surface. In this study, performance and free surface deformations of a two dimensional NACA0012 foil section, which is one chord length beneath the free surface is investigated numerically. Potential flow based iterative boundary element method is adopted, to predict the flow field. Mathematical formulation and numerical implementation of the present method is presented in detail. Numerical results reveals that, free surface has a significant impact on the lift force and wave drag of the foil. Variation of these forces with Froude number is presented. Besides, it is observed that, foil generates deformations on the free surface and the wave amplitudes increase with Froude Number.
\end{abstract}

Keywords: Iterative boundary element method; Potential flow, computational fluid dynamics (CFD), Submerged hydrofoil, NACA0012 foil, Free surface, Lift.

\footnotetext{
*Sorumlu Yazar: tcosgun@yildiz.edu.tr
} 


\section{Giriş}

Gemi inşaatı ve ulaştırma alanındaki yıllar içindeki gelişim neticesinde yüksek hızlı teknelere olan ilgi de artmıştır. Klasik deplasman tipi tekneler, artan direnç karakteristikleri sebebiyle ancak belirli hızlara ulaşabilirler. Daha yüksek hızlara çıkabilmek için, geleneksel tekne yapısından daha farklı özelliklere sahip tekne tipleri kullanılır. Yüksek hızlı tekneler olarak adlandırılan bu gemi tipleri, genel olarak kayıcı tekneler ve hidrofoilli tekneler olarak iki ana tipte sinıflandırılabilir (Chen,2011). Oldukça yüksek hızlara ulaşabilen hidrofoilli tekneler, gezinti tekneleri, ticari gemiler ve askeri tekneler gibi pek çok alanda kullanılmaktadır.

Hidrofoilli teknelerin çalışma prensibi, ana gövdeye bağlı çeşitli sayılardaki kanatlardan elde edilen kaldırma kuvveti yardımıyla, tekne deplasmanını azaltmaya dayanır. Su altında ve genellikle serbest yüzeye paralel olarak ilerleyen kanat yapıları, tekne hızlandıkça bir kaldırma kuvveti üretirler. Bu kaldırma kuvveti neticesinde tekne su yüzeyinden tamamen ya da kısmen ayrılır. Bu sayede geminin ıslak alanı önemli ölçüde azaltılarak büyük bir direnç kazanımı sağlanır.

Bir akışkan içerisinde ilerleyen kanatların geometrisi ya da hücum açısı sayesinde kaldırma kuvveti üretmesi bilinen bir durumdur. Ancak, hidrofoilli teknelerde kullanılan kanat yapıları, serbest bir akışkan ortamında değil, serbest yüzeyin yakınında çalışırlar. Serbest yüzey yakınında çalışan kanatlar, oluşan karşılıklı etkileşim dolayısıyla farklı karakteristiklere sahip olurlar ve serbest yüzeyin kanat performansı üzerindeki etkisinin dizayn aşamasında incelenmesi önem arz etmektedir (Bal, 2007).

Serbest yüzey yakınında ilerleyen kanatların performansı ve serbest yüzeyle etkileşimleri, pek çok çalışmaya konu olmuştur. Duncan (1983) deneysel çalışmasında, serbest yüzey altında ilerleyen iki boyutlu bir NACA0012 kanat formunu incelemiştir. Çalışmada farklı derinlikler ve üç farklı çalışma hızı test edilerek, kanat tarafindan oluşturulan dalga deformasyonu ve dalga direnci ölçülmüştür. Çalışmanın sonuçları arasında kaldırma kuvvetine dair bir ölçüm ise bulunmamaktadır. Diğer bir deneysel çalışmada ise, $\mathrm{Ni}$ ve diğ. (2019) serbest yüzey yakınında ilerleyen bir kanat üzerine slotlar yerleştirerek performansa etkisini incelemişlerdir. Çalışma sonucunda, slotlu yapının kanata ait kaldırma ve direnç özelliklerinde iyileşme sağladığı gözlenmiştir. Deneylerde tek bir Reynolds sayısı ve $\left(\operatorname{Re}=10^{5}\right)$ geniş bir aralıktaki hücum açıları kullanılmıştır.

Literatürde, deneysel çalışmaların yanında sayısal incelemelere de rastlanılmaktadır. Karim ve Ahammed (2012), RNG k-epsilon türbülans modelini kullanarak NACA0012 kanat kesiti etrafındaki kavitasyonlu viskoz akım alanını sayısal olarak modellemişlerdir. Çalışma sonucunda, kavitasyon dinamiklerine bağlı olarak kanat yüzeyindeki basınç dalgalanmaları hidrodinamik katsayılardaki salınımları gözlemlemişlerdir. Eleni ve diğ. (2012), sayısal modellerle deneysel veriler arasına bağ kurmak amaciyla, iki boyutlu NACA0012 kanat kesiti etrafındaki ses altı akımı, üç farklı türbülans modeli kullanarak incelemişlerdir. Sonuç olarak, ticari HAD yazılımlarında kullanılan türbülans modellerinin yüksek hücum açılarındaki akımı modellemede yetersiz kaldığı vurgulanmıştır. Çakıcı ve Kınacı (2012), serbest yüzey yakınında çalışan iki boyutlu NACA0012 kanat kesitinin performansını ticari bir HAD yazılımı kullanarak incelemişlerdir. $5^{\circ}$ hücum açısında çalışan kanat kesitinin etfarındaki akış alanını viskoz olmayan akış kabulüyle çözmüşler ve sınır elemanlar metodu ile uyumlu sonuç verdiğini gözlemlemişlerdir. Karim ve diğ. (2014), serbest yüzey yakınında çalışan NACA0015 kesitine sahip iki boyutlu kanat etrafındaki viskoz akımı, sonlu hacimler yöntemi kullanarak incelemişlerdir. Çalışmada, tek bir kanat hızı ve farklı derinlikler kullanılarak, serbest yüzey üzerinde kanat tarafından oluşturulan dalga yapısı gözlenmiştir. Wu ve Chen (2016), serbest yüzey altındaki bir kanat etrafindaki kavitasyonu, sonlu hacimler yöntemi vasıtasıyla modellemişlerdir. Çalışmada kullanılan yöntemin serbest yüzey etkileşimi altındaki kanatta oluşan kavitasyonu yakalamadaki başarısı test edilmiştir. Ayrıca detaylı bir literatür incelemesi de sunulmuştur.

Batmış cisimler etrafındaki akımı modellemek için, viskoz akım temelli yöntemler kullanılabildiği gibi (Bakırcı 2020; Körpe ve diğ., 2019; Oktay and Kanat 2019), hesaplama açısından verimli ve başarılı bir yöntem olarak potansiyel akım temelinde çalışan sınır elemanları yöntemi de (Boundary Element Method (BEM)) kullanılmaktadır. Tarafder ve diğg. $(2019,2010)$ iki ve üç boyutlu NACA0012 kanat yapıları etrafındaki akımı modellemek için panel metodu kullanmışlardır. Çalışmada, analitik ve deneysel sonuçlarla yapılan karşılaştırmalar neticesinde, yöntemin oldukça etkili ve güvenilir olduğu gözlenmiştir. Hidrodinamik literatüründe de, BEM yöntemini kullanan önemli çalışmalar mevcuttur. Bal (1999), serbest yüzey yakınında çalışan iki boyutlu NACA4412 etrafındaki akımı incelemek için potansiyel akım temelli panel metodu kullanmıştır. Çalışmada Neumann tipi yerine Dirichlet tipi sınır koşulu kullanılmış, serbest yüzey ise lineer sınır koşulu ile modellenmiştir. Çalışmada farklı derinlik ve Froude sayılarının etkisi incelenmiş ve yöntem doğruluk açısından güvenilir bulunmuştur. Ghassemi ve diğ. (2010) batmış NACA0012 kesitli bir kanat etrafındaki akımı potansiyel akım kullanarak modellemişlerdir. Çalışmada birinci ve ikinci dereceden serbest yüzey sınır koşulları kullanılarak farklı derinlilerdeki kanat performansı incelenmiştir. Karaalioğlu ve Bal, (2015, 2017) iki ve üç boyutlu kanat yapıları etrafında oluşan kavitasyonu, sınır elemanları yöntemi kullanarak başarılı biçimde modellemişlerdir.

$\mathrm{Bu}$ çalışmada, serbest yüzey yakınında çalışan batmış iki boyutlu NACA0012 kanat kesiti etrafindaki akım sınır elemanları yöntemi kullanılarak incelenmiştir. $\mathrm{Bu}$ amaçla Laplace denklemi, Green'in ikinci teoremi kullanılarak tekil çözümler dağılımı şeklinde integral denklemine dönüştürülmüştür. Kanat düzlem (line) paneller ile temsil edilmiş ve genel çözüm, kanat üzerine dağılmış kaynak ve dipollerin toplamı biçiminde elde edilmiştir. Çalışmada bir kanat boyu derinlikte farklı Froude sayılarının etkisi incelenmiştir. Sonuçlar kaldırma katsayısı, dalga direnci ve serbest yüzey üzerinde oluşan dalga deformasyonları biçiminde sunulmuştur.

\section{2. Çözüm Yöntemi}

Çalışma birbiriyle bağlantılı iki bölümden oluşmaktadır. İlk bölüm "serbest akımda hareket eden kanat", ikinci bölüm ise "serbest yüzey etkisinde çalışan kanat" şeklinde isimlendirilmiştir. Geometrik detaylar, sınır koşulları, teorik altyapı gibi ilgili alt başlıklar, her bölüm içerisinde ayrı ayrı verilmiştir. Her iki bölümde de kullanılan yöntemin matematiği ayrıntılı biçimde sunulmuştur.

Çalışmanın ilk bölümünde, iki boyutlu NACA0012 kanat kesiti, serbest akım içerisinde potansiyel akım yaklaşımı ile 
modellenmiştir. Serbest yüzey olmadan yapılan bu modellemedeki amaç, oluşturulan kodun doğruluğunu test etmektir. Ayrıca, serbest akımda elde edilmiş sonuçlar serbest yüzeyli sonuçlarla kıyaslama açısından da bir temel oluşturmaktadır. Hesaplamalar farklı hücum açıları için tekrarlanmış ve sonuçlar Xfoil sonuçları ile doğrulanmıştır.

İkinci bölümde, kanat serbest yüzey altında olacak biçimde modellenmiştir. Sayısal sonuçlar literatürdeki mevcut deneysel verilerle doğrulanmıştır. Doğrulamanın ardından hesaplamalar farklı akış koşullarını da içerecek biçimde genişletilmiştir. Bir kord boyu derinlikte $(\mathrm{h} / \mathrm{c}=1$; burada $\mathrm{h}$ serbest yüzeyden olan derinlik, c ise kanatın kord boyudur) ve 0.4-1.2 aralığındaki farklı Froude sayıları $(F n=U / \sqrt{g c})$ incelenmiştir. Serbest yüzeyin kanat performansı üzerinde etkisinin en fazla düşük $\mathrm{h} / \mathrm{c}$ oranlarında gözlendiği ve artan derinlik oranıyla birlikte azaldığı literatürdeki benzer çalışmalarda belirtildiği için (Uslu ve Bal, 2008; Ghassemi,2010), mevcut çalışmadaki inceleme kanatın serbest yüzeye yakın olduğu durumda yapılmıştır.

Tüm sonuçlar, Fortran dilinde oluşturulan bir bilgisayar yazılımı ile elde edilmiştir

\section{Bölüm 1: Serbest Akımda Hareket Eden Kanat}

Serbest akım içerisinde (serbest yüzey olmadan) hareket eden kanat kesitini etrafındaki akımın potansiyel akım temelli sınır elemanları yöntemi kullanılarak modellenmesine dair sonuçlar bu bölümde verilmektedir

\subsection{Geometri ve Koşullar}

Bu çalışmada, 2-B NACA 0012 kanat kesiti kullanılmıştır. NACA formlu kanat kesitleri isimlendirilirken, dört rakamdan ilki kord boyutunun yüzdesi cinsinden kanatın maksimum kamburluğunu, ikinci rakam ise maksimum kamburluğun konumunu gösterir. İkinci ve üçüncü rakam ise kord boyunun yüzdesi cinsinden kanadın maksimum kalınlığını belirtir. Oldukça çok incelenmiş bir form olan NACA0012 kanat kesitinde de, ilk iki rakamın "00" olması kanatın simetrik yapısın1, "12" ise maksimum kalınlığının \%12 olduğunu göstermektedir (Abbot, 1959). NACA0012 kanat kesitinin simetrik yapısı, sayısal çalışmalarda konumsal ayrıklaştırma açısından avantajlar sunmaktadır. Ayrıca, farklı alanlardaki hem deneysel hem de sayısal pek çok çalışmaya konu olması da araştırmacılara sonuçlarını kıyaslama imkanı tanımaktadır (Huang ve diğ.,2004; Sharma ve Clement,2014; Kinaci, 2015; Raj,2017). Kanatın geometrisine ait detaylar ve koordinat sistemi, Şekil 1'de görülmektedir.

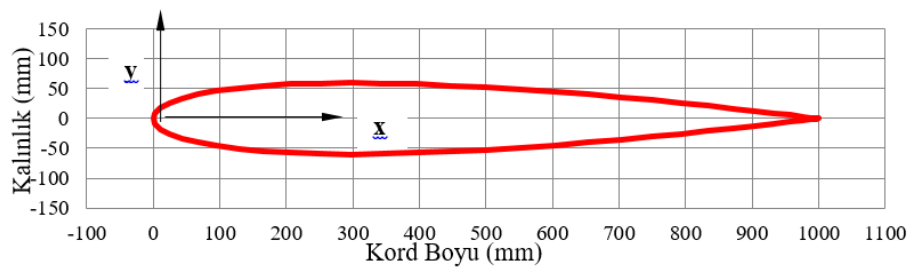

Şekil 1. NACA 0012 kanat geometrisi

Sabit bir gelen akım hızında, kanatın hücum açısı $0^{\circ}$ dan $10^{\circ}$ ye kadar, 2 derecelik aralıklarla değiştirilmiştir

\subsection{Matematik Formülasyon}

Potansiyel akımın gereği olarak, akışkan sıkıştırılamaz, viskoz olmayan ve dönümsüz (irrotasyonal) kabul edilmiştir. Serbest akım hızı "U”, kanat yüzeyine yerleştirilen koordinat düzleminin X-Z eksenindedir. Hücum açısı $\alpha$, gelen akım hızı ile $\mathrm{x}$ ekseni arasındaki açı olarak ölçülmüştür.

Toplam hiz potansiyeli, serbest akım potansiyeli ve perturbasyon potansiyelinin toplamı cinsinden yazılırsa (Bal ,2011; Lee et al. ,2000);

$$
\Phi=U x+\phi
$$

Burada $\phi$ pertürbasyon potansiyelidir. Toplam h1z potansiyeli “ $\Phi$ ”, “ $\Omega$ ” çözüm alanı içerisinde Laplace denklemini sağlamalıdır;

$$
\nabla^{2} \Phi=0, \nabla^{2}(U x+\phi)=0, \nabla^{2} \phi=0
$$

Çözüm alanı $\Omega$ kanat yüzeyi $S_{H}$, iz yüzeyi $S_{W}$ ve dış kontrol yüzeyi $S_{\infty}$ ile sınırlanmaktadır. Çözüm alanı ve ilgili notasyonun çözüm alanı üzerinde gösterimi Şekil 2'de sunulmuştur.

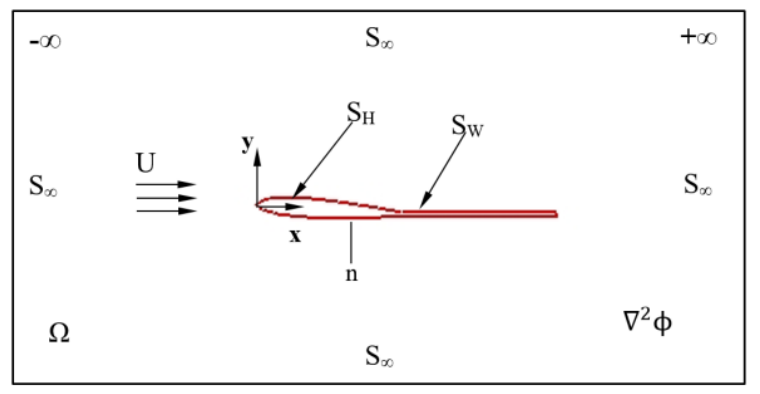

Şekil 2. Çözüm alanı ve ilgili notasyon

Problem, sınır koşulları aşağıdaki gibi belirlenerek oluşturulabilir:

Kinematik Cisim (Kinematic body) Sınır Koşulu:

$$
\frac{\partial \phi}{\partial n}=-\vec{U} \cdot \vec{n} \text {, on } S_{H}
$$

Burada $\vec{n}$ normal birim vektördür.

Sonsuzdaki Radyasyon (Radiation) sınır koşulu:

$$
\nabla \phi \rightarrow 0
$$

Kanatın çıkış ucundaki Kutta koşulu:

$$
\nabla \phi=\operatorname{sonlu}(\text { finite })
$$

İz yüzeyi için:

$$
P_{U}=P_{L}=P
$$

Akım yönündeki hız yüzey boyunca sürekli olmalıdır:

$$
\vec{t} \cdot\left(\vec{V}_{U}-\vec{V}_{L}\right)=0
$$


Burada $U$ ve $L$ alt indisleri sirasıyla izin üst ve alt yüzeylerini, $\mathrm{V}$ ve $\mathrm{P}$ ise hiz ve basıncı ifade etmektedir. $\vec{t}$ ortalama hız yönündeki birim vektördür. İz yüzeyi $S_{W}$ sıfır kalınlıktadır ve yüzeydeki basınç sıçraması da sıfırdır. Ancak potansiyelde bir sıçrama bulunmaktadır;

$$
\Delta \phi=\phi_{U}-\phi_{L}=\Gamma
$$

Burada sabit $\Gamma$ cisim etrafındaki sirkülasyonu ifade eder.

\subsection{Sayısal Uygulama}

Hiz potansiyeli $\phi$ Green teoremi uygulanarak kanat yüzeyindeki bir integral denklemi biçiminde yazılabilir.

$$
\frac{1}{2} \phi=\int_{S_{H}}\left(\phi \frac{\partial G}{\partial n}-G \frac{\partial \phi}{\partial n}\right) d S+\int_{S_{W}} \Delta \phi_{W} \frac{\partial G}{\partial n} d S
$$

burada $S_{B}$ ve $S_{W}$ sirasiyla kanat ve iz yüzeyleridir. Green fonksiyonu $\mathrm{G}=\frac{1}{2 \pi} \ln r, r$ tekilliklerin lokasyon vektörüdür.

Çözümü elde edebilmek için, yüzey $\mathrm{S}_{\mathrm{H}}, \mathrm{N}$ adet panele bölünür ve denklem 9'un ayrıklaştırılmış formu yüzey üzerinde şu şekilde ifade edilir (Tarafder et al. ,2010);

$$
\frac{1}{2} \phi^{i}=\sum_{j=1}^{N} \int_{S_{H}+S_{W}} \phi \frac{\partial G}{\partial n} d S-\sum_{j=1}^{N} \int_{S_{B}} \mathrm{G} \frac{\partial \phi}{\partial n} d S
$$

Burada $\phi$ ve $\frac{\partial \phi}{\partial n}$ her eleman için sabittir, böylece integral dışına çıkarılabilir. Denklem (10) şu biçime dönüşür;

$$
\begin{aligned}
& \frac{1}{2} \phi^{i}-\sum_{j=1}^{N}\left(\int_{S_{H}+S_{W}} \frac{\partial G}{\partial n} d S\right) \phi^{j}=-\sum_{j=1}^{N}\left(\int_{S_{H}} \mathrm{G} d S\right) \frac{\partial \phi^{j}}{\partial n}(11) \\
& \int_{S_{H}+S_{W}} \frac{\partial G}{\partial n} d S \equiv \hat{H}_{i j} \\
& \int_{S_{H}} \mathrm{G} d S \equiv G_{i j}
\end{aligned}
$$

İki boyutlu sınır elemanları yöntemini uygulayabilmek için, kanat 60 doğrusal elemana ayrılmıştır. Kullanılan elemanlar, kanatın giriş ve çıkış ucu yakınlarında sıklaştırılmıştır. Kanat yüzeyinin panellere bölünmüş görünümü Şekil 3 'te görülmektedir.

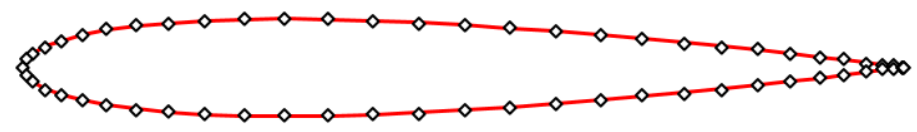

\section{Şekil 3. NACA 0012 kanat kesitinin panellere bölünmüş görünümü}

$\mathrm{Bu}$ elemanlar gerçek geometriyi düzgün paneller biçiminde temsil eder. $G_{i j}$ standart Gaussian quadrature kullanarak sayısal olarak bulunurken, $H_{i j}$ analitik olarak hesaplanır. $\mathrm{Bu}$ konu hakkında daha ayrıntılı bilgi ilgili referansta (Katsikadelis, 2002) bulunabilir. Denklem (11) aşağıdaki biçimde ifade yazılabilir;

$$
\sum_{j=1}^{N} H_{i j} \phi_{j}=-\sum_{j=1}^{N} G_{i j} \frac{\partial \phi^{j}}{\partial n}
$$

Burada

$$
H_{i j}=\frac{1}{2} \delta_{i j}-\hat{H}_{\hat{\imath} j}
$$

Etki katsayısı belirlenirken, her birleşim noktasındaki perturbasyon potansiyelleri " $H_{i j}$ " $\mathrm{N}+1$ sayıda bilinmeyen içeren, $N \times N$ boyutlarında bir etki matrisi verir (burada iz potansiyeli $\Delta \phi_{W}(N+1)$. bilinmeyendir). Ek denklem, kutta koşulunu uygulayarak elde edilir;

$$
\left(\phi_{1}-\phi_{N}\right)-\Delta \phi_{W}=0
$$

Yukarıda verilen cebirsel denklem seti Gauss eleme yöntemi ile çözülmüştür. Sıkıştırılamaz, viskoz olmayan, dönümsüz serbest akımdaki hidrodinamik kaldırma kuvveti, $L$, şu şekilde verilebilir;

$$
L=\rho U \Gamma
$$

Burada $\rho$ akışkanın yoğunluğu, $\Gamma$ ise cisim etrafındaki sirkülasyondur.

\subsection{Sayısal Doğrulama}

Mevcut çalışmadaki sınır elemanlarılar yöntemi ile elde edilmiş sayısal sonuçların, XFoil ile elde edilen sonuçlarla kıyaslaması Şekil 4'te verilmektedir. XFoil yazılımı (Drela,1989), düşük Reynolds sayılarında çalışan kanat formlarının performansının değerlendirilmesi imkânı sunan açık kaynaklı bir koddur. İlk olarak Massachusetts Institute of Technology (MIT) tarafından geliştirilmiş ve kullanıma sunulmuştur. Panel metod yaklaşımıyla çalı(â)XFoil kodu, sınır tabaka parametrelerinin hesaplanması için bir integral sınır tabaka formülasyonunu da içerir. Oldukça hızlı ve yüksek güvenilirlikte sonuçlar sunan XFoil kodu phesk çok araştırmacı tarafından kullanılmaktadır (Ganesh Ram ve diğ, 2014; Morgado ve diğ, 2016; Nguyen ve Lee., 2018). Şekil 4'te sunulan kıyaslamada, elde edilen sonuçların, yüksek doğrulukta olduğu ve kaldırma kuvveti katsayısı $C_{L}$ 'in hücum açısıyla değişimini başarılı biçimde temsil ettiği görülmektedir.

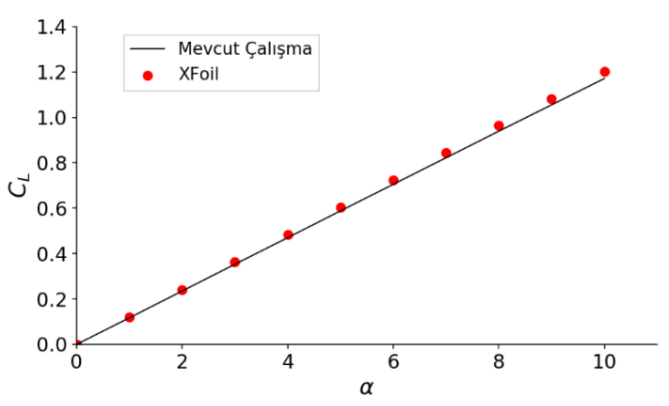

Şekil 4 Hesaplanan kaldırma katsayılarının XFoil sonuçlart ile kıyaslanması 
Hidrodinamik kaldırmanın yanında, basınç katsayıları da XFoil sonuçları ile doğrulanmıştır. Basınç katsayısını elde edebilmek için, her birleşme noktasındaki lokal teğetsel hız, hız potansiyelini teğetsel doğrultuda türevlenir (Bal,1999);

$$
V_{t_{j}}=\frac{\phi_{j+1}-\phi_{j}}{\Delta l_{j}}+U \vec{t}
$$

a)

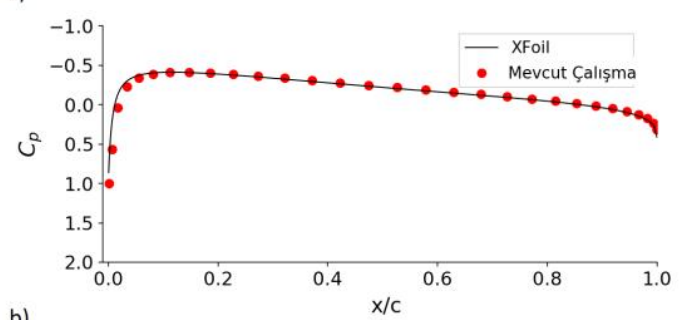

b)

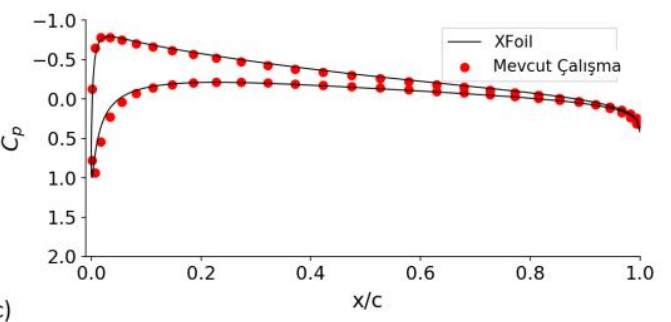

c)

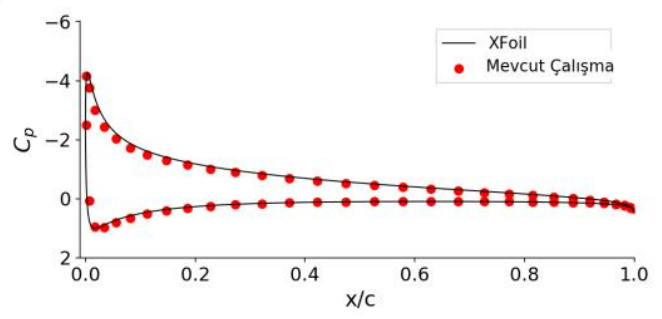

Şekil 5 Kanat üzerindeki basınç katsayısı dă̆ılımlarının hücum açısıyla değişimi $\left.\left.a) \alpha=0^{\circ}, b\right) \alpha=2^{\circ}, c\right) \alpha=8^{\circ}$

Daha sonra, basınç katsayısı Bernoulli denklemi kullanılarak bulunabilir:

$$
C_{P_{j}}=\frac{P_{j}-P_{\infty}}{\frac{1}{2} \rho U^{2}}=1-\left(\frac{V_{t_{j}}}{U}\right)^{2}
$$

Şekil 5, hesaplanan kanat yüzeyi basınç dağılımları ile XFoil sonuçlarının farklı hücum açılarındaki karşılaştırılmasını göstermektedir. Mevcut çalışmada elde edilen basınç katsayıları, hem yüksek, hem de düşük hücum açılarında Xfoil sonuçları ile yüksek uyum göstermektedir.

\section{Bölüm 2: Serbest Yüzey Yakınında Çalışan Kanat}

Batmış bir kanat kesitine serbest yüzey etkisinin sınır elemanları yöntemi kullanılarak sayısal simulasyonu bu bölümde sunulmaktadır

\subsection{Geometri ve Koşullar}

Serbest yüzey etkisi altındaki NACA 0012 kanat kesiti etrafındaki akım iteratif sınır elemanları yöntemini ile e-ISSN: 2148-2683 çözülmüştür. Serbest yüzeyi temsil etmek için lineer serbest yüzey sınır koşulu uygulanmıştır. Bu bölümde de, Bölüm 1'deki ile aynı kanat geometrisi kullanılmıştır. Çözüm alanının geometrik detayları ve ilgili notasyonun çözüm alanı üzerinde gösterimi Şekil 6'da verilmiştir.

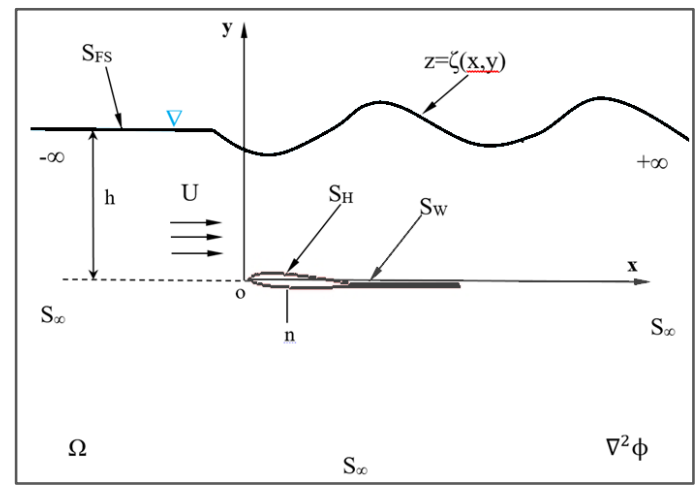

Şekil 6 Çözüm alanının geometrik ayrıntıları

Sayısal sonuçların doğrulanması amacıyla, NACA0012 kanat kesitinin analizi Duncan (1983) tarafindan gerçekleştirilen deneysel çalışmadakine benzer koşullarda yapılmıştır. Kanatın kord boyu $0.203 \mathrm{~m}$, ve sabit akım hızı (U) $0.8 \mathrm{~ms}^{-1}$ dir. $\mathrm{Bu}$ durumda Froude sayısı 0.571 olarak hesaplanmaktadır. Froude sayısı şu şekilde hesaplanmıştır $F n=U / \sqrt{g c}$ ( $c$ : kord boyu). Kanata ait hücum açısı ise $\alpha=5^{\circ}$ 'dir. Kanatın serbest yüzeyden uzaklığ $\mathrm{h}=21.0 \mathrm{~cm}$ 'dir. Serbest yüzeyi temsil eden paneller yukarı akım yönünde (upstream) $2.0 \lambda$ ( $\lambda=2 \pi U^{2} / g$ : dalga boyu) aşağı akım yönünde (downstream) ise $3.5 \lambda$ boyunca uzanmaktadır. Kanat yüzeyi ve serbest yüzeyde kullanılan panel sayıları sırasıyla 60 ve 150 'dir.

Doğrulama senaryosundaki batma oranı $\mathrm{h} / \mathrm{c}=1.034$ 'dır. Çalışmanın devamında ise batma oranı $\mathrm{h} / \mathrm{c}=1.0$ olarak alınmıştır. Burada, "h" kanat ve serbest yüzey arasındaki düşey mesafedir.

\subsection{Matematik Formülasyon}

Sonsuz derinlikteki bir akışkanın yüzeyinde serbest U hızıyla hareket eden iki boyutlu bir kanat düşünelim. Serbest yüzey üzerinde ek olarak dört sınır koşulu gerekir.

Kinematik serbest yüzey koşulu:

$$
\frac{D F(x, y, z)}{D t}=0 \text { on } z=h+\zeta(x, y, z)
$$

Dinamik serbest yüzey koşulu:

Bernoulli denkleminden, aşağıdaki gibi yazılabilir;

$$
\frac{1}{2}\left[(\nabla \phi)^{2}-U^{2}\right]+g \zeta=0
$$

Burada g yer çekimi ivmesidir. Denklem (18) ve (19) u birbirlerinden çıkararak ve ikinci dereceden terimleri ihmal 
ederek, doğrusal serbest yüzey sınır koşulu aşağıdaki gibi bulunabilir;

$$
\frac{\partial^{2} \phi}{\partial x^{2}}+k_{0} \frac{\partial \phi}{\partial z}=0 \text { on } z=h
$$

burada $k_{0}=g / U^{2}$ dalga sayısıdır. Dalga profili için doğrusallaştırılmış denklem şu şekildedir;

$$
\zeta=-\frac{U}{g} \frac{\partial \phi}{\partial z}
$$

\section{Radyasyon sınır koşulu:}

Giriş yönünde kanat önünde herhangi bir bozulmanın (no distrubance) olmaması için bu sınır şartı tanımlanmıştır. Akış yönünde radyasyon sınır koşulu (Tarafder and Suzuki, 2007);

$$
x \rightarrow-\infty \frac{\partial^{2} \phi}{\partial x^{2}}=\frac{\partial \phi}{\partial x}=0, x \rightarrow \infty
$$

\subsection{Sayisal Uygulama}

Kanat üzerindeki bilinmeyen pertürbasyon potansiyellerini tespit etmek için iteratif sınır elemanları yöntemi kullanılmıştır. Green'in üçüncü teoremine göre, kanat yüzeyi ve serbest yüzey üzerindeki petürbasyon potansiyelleri şu şekilde ifade edilebilir;

$$
\frac{1}{2} \phi=\int_{S_{F S}+S_{H}}\left(\phi \frac{\partial G}{\partial n}-G \frac{\partial \phi}{\partial n}\right) d S+\int_{S_{W}} \Delta \phi_{W} \frac{\partial G}{\partial n} d S
$$

burada $\mathrm{S}_{\mathrm{FS}}$ serbest yüzey sınırıdır. İteratif sınır elemanları yöntemi iki bölümden oluşur: (i) kanat bölümü: kanat üzerindeki bilinmeyen pertürbasyon potansiyellerini çözer, (ii) serbest yüzey bölümü: serbest yüzey üzerindeki pertürbasyon potansiyellerini çözer. Akış içerisinde kanatın etkisiyle oluşan potansiyeller de şu şekilde yazılabilir;

$\phi_{H}=\int_{S_{H}}\left(\phi \frac{\partial G}{\partial n}-G \frac{\partial \phi}{\partial n}\right) d S+\int_{S_{W}} \Delta \phi_{W} \frac{\partial G}{\partial n} d S$ ise;

Diğer yandan, serbest yüzeyin etkisiyle oluşan potansiyeller

$$
\phi_{F S}=\int_{S_{F S}}\left(\phi \frac{\partial G}{\partial n}-G \frac{\partial \phi}{\partial n}\right) d S
$$

Şeklinde ifade edilir. Denklem (25) ve denklem (23)'ü birbirlerinden çıkararak, kanat için integral denklemi aşağıdaki biçimde elde edilir;

$$
\frac{1}{2} \phi_{H}=\int_{S_{H}}\left(\phi \frac{\partial G}{\partial n}-G \frac{\partial \phi}{\partial n}\right) d S+\int_{S_{W}} \Delta \phi_{W} \frac{\partial G}{\partial n} d S+\phi_{F S}
$$

Ve denklem (24) ve denklem (23)'ü birbirlerinden çıkarırsak, serbest yüzey için integral denklemi elde edilir;

$$
\frac{1}{2} \phi_{F S}=\int_{S_{F S}}\left(\phi \frac{\partial G}{\partial n}-G \frac{\partial \phi}{\partial n}\right) d S+\phi_{H}
$$

Kanat yüzeyi için kinematik sınır koşulunu ve serbest yüzey için de doğrusallaştırılmış serbest yüzey sınır koşulunu uygularsak, denklem (26) ve (27) şu şekilde yazılabilir;

$$
\frac{1}{2} \phi_{H}=\int_{S_{H}}\left(\phi \frac{\partial G}{\partial n}+(\vec{U} \cdot \vec{n}) G\right) d S+\int_{S_{W}} \Delta \phi_{W} \frac{\partial G}{\partial n} d S+\phi_{F S}
$$

$$
\frac{1}{2} \phi_{F S}=\int_{S_{F S}}\left(\phi \frac{\partial G}{\partial n}+\frac{\partial^{2} \phi}{\partial x^{2}} \frac{G}{k_{0}}\right) d S+\phi_{H}
$$

$\mathrm{Bu}$ nokta ile ilgili daha detaylı bilgi, ilgili referansta (Bal ve diğ.,2001) bulunabilir. Bu çalışmada, $\partial^{2} \phi / \partial x^{2}$ terimi dördüncü dereceden geri sonlu farklar metodu kullanılarak çözülmüştür. Serbest yüzey panelleri eş boyutlarda oluşturulmuştur ve $\phi$ 'in x’e göre birinci ve ikinci türevleri aşağıdaki gibidir;

$$
\frac{\partial \phi}{\partial x}=\frac{1}{12 D x}\left(25 \phi_{i}-48 \phi_{i-1}+36 \phi_{i-2}-16 \phi_{i-3}+3 \phi_{i-4}\right)
$$

$$
\frac{\partial^{2} \phi}{\partial x^{2}}=\frac{1}{180 D x^{2}}\left(\begin{array}{l}
812 \phi_{i}-3132 \phi_{i-1}+5265 \phi_{i-2} \\
-5080 \phi_{i-3}+2970 \phi_{i-4}-972 \phi_{i-5} \\
+137 \phi_{i-6}
\end{array}\right)
$$

Burada Dx serbest yüzey panel boyutudur. $\frac{\partial^{2} \phi}{\partial x^{2}}$ terimi denklem (31) kullanılarak hesaplanabilir. Akış yönlü (upstream) dalgaların oluşumunu engellemek için, $\phi$ 'in x'e göre birinci ve ikinci türevi sıfıra eşitlenir (Bal et al.,2001).

İteratif sınır elemanları yöntemi kullanılarak kanat üzerindeki kaldırma ve direnç kuvvetleri, basınç dağılımı ve serbest yüzey deformasyonları tespit edilebilir. İki boyutlu bir kanat kesitine ait sonuçlar bir sonraki bölümde sunulmaktadır.

\section{Sayısal Sonuçlar ve Tartışma}

Serbest yüzey yakınında çalışan bir kanat kesiti etrafındaki akım alanını incelemeden önce, kullanılan yöntemin ve oluşturulan yazılımın doğruluğu test edilmiştir. Bu amaçla, önce serbest yüzey altındaki noktasal bir girdabın oluşturduğu dalga deformasyonu analitik sonuçlar ile karşılaştırılmıştır. Daha sonra da, serbest yüzey altında çalışan bir kanat kesitine ait dalga deformasyonları, literatürdeki mevcut deneysel sonuçlarla kıyaslanarak doğruluğu araştırılmıştır. Serbest yüzey altında hareket eden noktasal girdap (vorteks) etrafindaki akış, Wehausen and Laitone (1960) tarafindan analitik olarak açıklanmıştır. Noktasal kaynak tarafindan oluşturulan dalga deformasyonları hesaplanmış ve mevcut sayısal sonuçlarla kıyaslaması Şekil 7'de sunulmuştur. Noktasal kaynağın şiddeti 
$\frac{\Gamma}{2 \pi}=-2.7 \mathrm{ft}^{2} / \mathrm{sn}$, serbest akım hızı $\mathrm{U}=10 \mathrm{ft} / \mathrm{sn}$, batma derinliğ ise $\mathrm{h}=4.5 \mathrm{ft}$ 'dir. Serbest yüzeyi temsil eden paneller yukarı akım yönünde $2.0 \lambda\left(\lambda=2 \pi U^{2} / g\right)$ aşağı akım yönünde ise $3.5 \lambda$ boyunca uzanmaktadır. Serbest yüzeyde kullanılan panel sayısı 150 'dir.

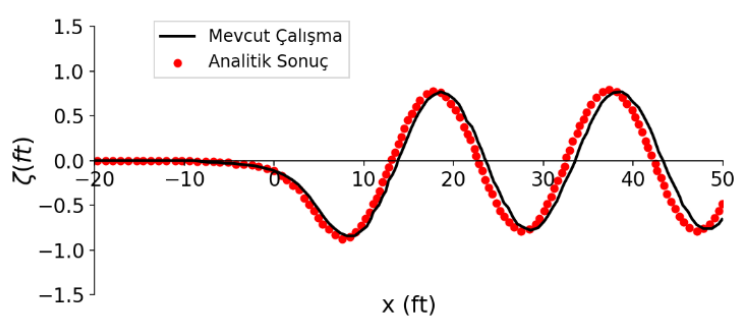

\section{Şekil 7 Bir noktasal kaynak için dalga deformasyonlarının karşılaştırılması}

İteratif sınır elemanları yöntemi kullanılarak hesaplanan, su altında ilerleyen noktasal bir girdaba ait dalga deformasyonlarının analitik sonuçlarla karşılaştırılması Şekil 7'de görülmektedir. Şekilde görüldüğü gibi mevcut sonuçlar, analitik sonuçlarla yüksek uyum içerisindedir.

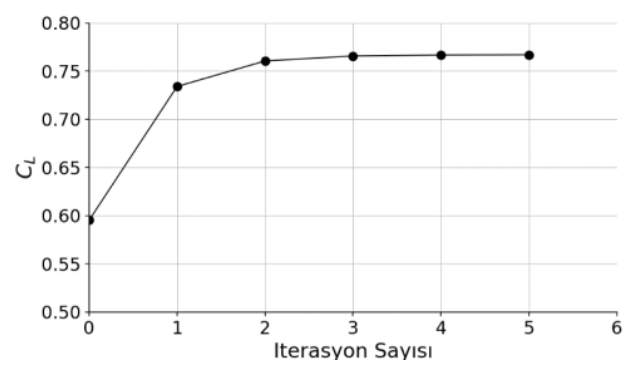

Şekil 8 NACA 0012 için kaldırma katsayısının iterasyon sayısına

$$
\text { göre değişimi }\left(F n=0.577, \alpha=5^{\circ}, h / c=1.034\right)
$$

Noktasal kaynak ile yapılan doğrulama çalışmasından sonra, iteratif sınır elemanları yöntemi NACA0012 kanat kesitine uygulanmıştır. Buradan sonraki tüm hesaplamalarda hücum açısı $\alpha=5^{\circ}$ 'dir. Hesaplanan kaldırma katsayılarının iterasyon sayısına göre değişimi Şekil 8'de görülmektedir. Şekil incelendiğinde, en fazla beş iterasyonun güvenilir sonuçlar elde etmek için yeterli olduğu görülebilmektedir. Ayrıca, kritik bölgelerdeki dalga yüksekliği değerleri arasındaki fark da sürekli olarak hesaplanmış ve farkın $10^{-4}$ mertebesinde olup olmadığı kontrol edilmiştir.

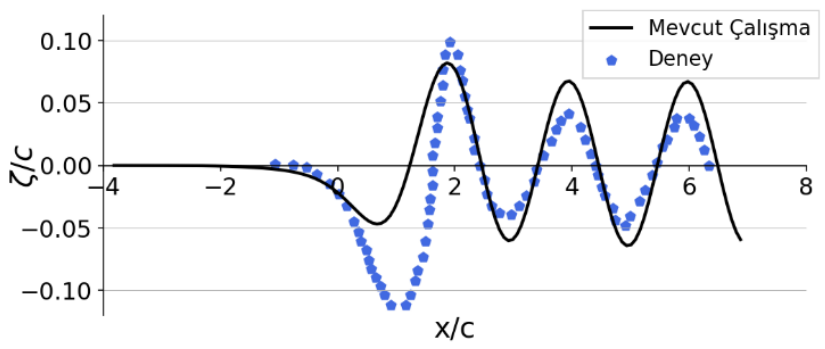

Şekil 9 NACA 0012 için dalga profillerinin karşılaştırılması $\left(F n=0.577, \alpha=5^{\circ}, h / c=1.034\right)$
Şekil 9, hesaplanan dalga profilinin, literatürdeki mevcut deneysel verilerle (Duncan,1983) karşılaştırmasını göstermektedir. Sayısal ve deneysel sonuçların genel olarak yüksek uyumda olduğu görülmektedir. Dalga boyları aynı mertebededir. Ancak dalga tepe ve çukurları arasında bir miktar farklılık gözlenmektedir. $\mathrm{Bu}$ durumun, doğrusallaştırılmış serbest yüzey sınır koşulundan kaynaklandığı düşünülmektedir.

Serbest yüzey altında ilerleyen kanat kesitine ait kaldırma katsayısının Froude Sayısı (Fn) ile değişimi Şekil 10'da verilmiştir. Şekilde incelenen derinlik bir kanat boyudur $(\mathrm{h} / \mathrm{c}=1.0)$. Potansiyel akım yaklaşımında, serbest akımda ve serbest su yüzeyi etkisi olmadan çalışan bir kanatta oluşan kaldırma kuvvetinin Froude sayısından bağımsız olması beklenir. Şekilde sunulan sayısal sonuçlar ise, kanat serbest yüzey yakınında çalışırken kaldırma kuvvetinin çalışma hızından önemli oranda etkilendiğini göstermektedir. Kanat üzerindeki serbest yüzey etkisi, Froude sayısının düşük ve yüksek değerleri için farklı yönlerdedir. Düşük Fn değerleri kanat tarafından üretilen kaldırma kuvvetinde artış sağlamaktadır. Ancak Fn=0.7 gibi belirli bir değerden sonra, Fn'deki artış kaldırma kuvvetinde kayba neden olmaktadır. Fn sayısının daha da büyük değerleri için, hidrodinamik kaldırma kuvveti neredeyse sabit bir değere ulaşmaktadır.

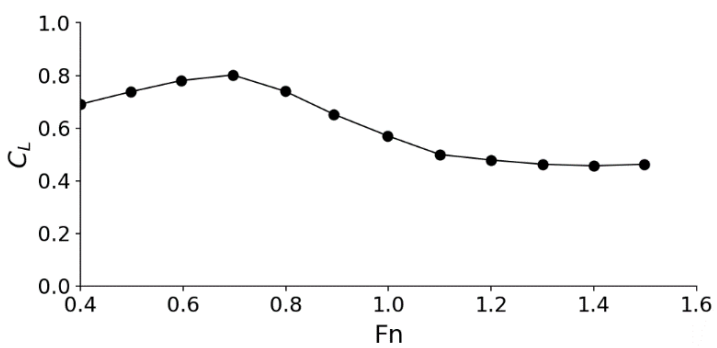

\section{Şekil 10 Kaldırma katsayısının Fn ile değişimi}

Direnç katsayısı, $C_{D}$, enerjinin korunumu kanununu uygulayarak hesaplanır. Potansiyel akım temelli hesaplamalarda sürtünme kuvveti olmadığı için, buradaki direnç dalga direncidir (dalga yapma direnci). Kanadı hareket ettirmek için gerekli olan enerjinin dalga tarafindan taşınan enerjiye eşit olması gerektiğinden; (Bal et al.,2001; Newmann,1977) ;

$$
D U_{\infty}=\frac{1}{2} \rho g\left(\frac{H^{2}}{4}\right) C_{g}
$$

Burada D kanatın direnci, $C_{g}$ dalga grup hızı, $\mathrm{H}$ dalga yüksekliği, $\rho$ ise akışkanın yoğunluğudur. Derin su için dalga grup hızı şu şekilde yazılabilir;

$$
\mathrm{C}_{\mathrm{g}}=\frac{\mathrm{U}_{\infty}}{2}
$$

$D=0.5 \rho U_{\infty}^{2} c C_{D} \quad$ bağıntısını kullanarak, $C_{D} \quad$ dalga yüksekliği cinsinden şu şekilde yazılabilir;

$$
\mathrm{C}_{\mathrm{D}}=\frac{\mathrm{gH}^{2}}{8 \mathrm{U}_{\infty}^{2} \mathrm{c}}
$$


Dalga direnci katsayının Froude sayısı ile değişimi Şekil 11 'de görülmektedir. Dalga direncinin değişim trendi de kaldırma katsayısının Fn ile değişimine oldukça benzerdir. Froude sayısının düşük değerleri için hızdaki artış dalga direncinin de artmasına neden olmaktadır. $F n=0.8$ değerinden sonraki operasyon hızlarda ise, dalga direnci hızlı bir biçimde düşmektedir. 1.0'in üzerindeki Fn değerleri için dalga direncinin düşüş grafiğindeki eğim azalmaktadır.

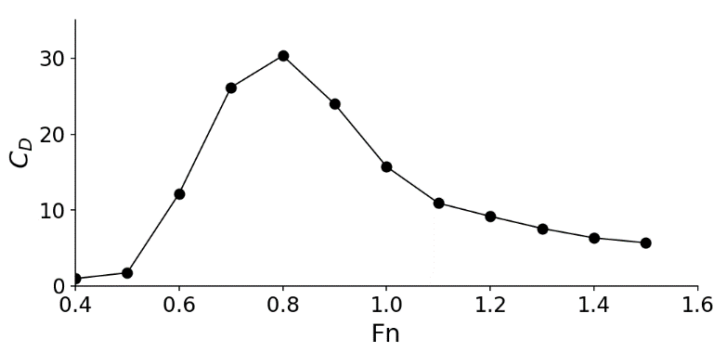

Şekil 11 Dalga direncinin Fn ile değişimi

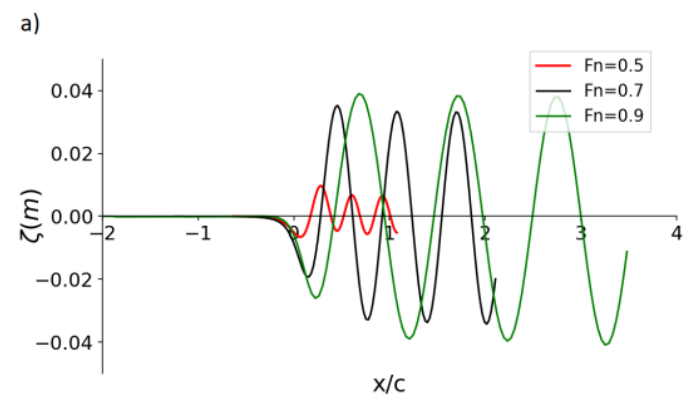

b)

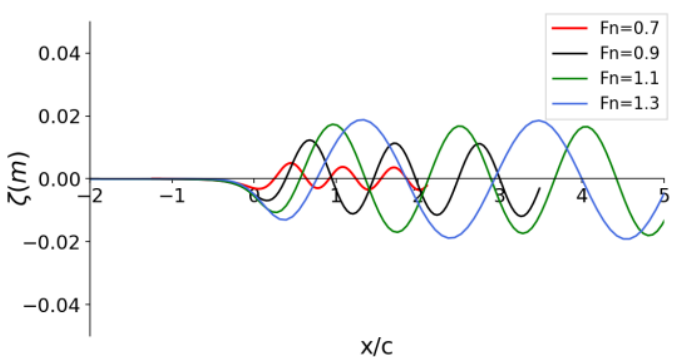

Şekil 12 Serbest yüzey deformasyonlarının Fn ile değişimi

( a) $h / c=1.0, b) h / c=1.5, c) h / c=2.0)$

Yüzey altında hareket eden kanat tarafından, serbest yüzey üzerinde dalga deformasyonları oluşturulur. $\mathrm{Bu}$ dalga profillerinin serbest Fn sayısı ile değişimi Şekil 12'de gösterilmektedir. Daha önce de belirtildiği üzere, serbest yüzey, akım yukarısında $2.0 \lambda$, akım aşağı yönünde ise $3.5 \lambda$ olacak şekilde sabit büyüklükte panellerle temsil edilmiştir. $\mathrm{Bu}$ durumda, çözüm algoritmasının akım aşağısındaki (downstream) yönde 3.5 dalga boyu kadar bir serbest yüzey hesaplayacağ anlamına gelir. Şekil 12'de görülen veri çizgilerinin x yönünde farklı uzunlukta olmasının nedeni budur. Şekilde görüldüğü üzere, kanat tarafından oluşturulan dalga tepe ve çukurlarının genlikleri Fn ile birlikte artmaktadır. Fn=0.5'deki dalga genlikleri, diğer hızlara kıyasla çok daha küçüktür. Artan Fn dalga genliklerinin yükselmesine neden olmuşsa da, 0.7 ve 0.9 Froude sayılarındaki dalga genlikleri birbirine oldukça yakındır. Yani Fn sayısının dalga genlikleri üzerindeki etkisi, düşük Fn'lerde daha belirgindir. Serbest yüzeydeki dalga deformasyonları incelenirken, farklı bir derinlikte daha $(\mathrm{h} / \mathrm{c}=2.0)$ hesaplama yapılmıştır. Şekil 12.b'de görüldüğü gibi, kanat kesitinin serbest yüzeye olan yakınlığının azalması, kanatın serbest yüzeyde oluşturduğu etkinin de azalmasına neden olmaktadır. $\mathrm{Bu}$ durum literatürdeki benzer çalışmalarda da gözlenmiştir (Ali,2010; Hoque,2017). Derinlik oranı arttığında, dalga genlikleri önemli oranda düşmektedir. Ayrıca Froude sayısının dalga genlikleri üzerindeki etkisi de benzer biçimde azalmaktadır.

\section{Değerlendirme}

Bu çalışmada, serbest yüzey yakınında çalışan iki boyutlu bir NACA0012 kanat kesiti etrafındaki akışın sayısal incelemesi yapılmıştır. Akım alanını modellemek için potansiyel akım temelli iteratif sınır elemanları yöntemi kullanılmıştır. Kullanılan yöntemin matematik formulasyonu ayrıntılı biçimde sunulmuştur. Çalışmanın ilk bölümünde, mevcut yaklaşımın doğrulanması amacıyla serbest akımda hareket eden bir kanat etrafındaki akım çözülmüştür. İkinci kısımda ise, aynı kanat kesiti serbest akım yakınında hareket ederken modellenmiştir. Sayısal sonuçlar literatürdeki deneysel verilerle doğrulanmış ve sınır elemanları yönteminin serbest yüzeyli akışları incelemek için etkin ve güvenilir bir yöntem olduğu görülmüştür.

Sayısal sonuçlar, serbest yüzey varlığının kanatların performansı üzerinde etkili olduğunu göstermektedir. Bu etki, artan Froude sayılarına göre değişmektedir. Düşük Fn'lerde kaldırma katsayısı artarken, belirli bir değerden sonra düşmeye başlamaktadır. Benzer bir eğilim dalga direnci üzerinde de mevcuttur. Kanat tarafindan serbest yüzey üzerinde oluşturulan dalga deformasyonları incelendiğinde, artan Fn ile birlikte, oluşan dalganın genliği de artmaktadır. Bu artış düşük çalışma hızlarında daha belirgindir. Kanadın serbest yüzeye yakınlığının azalması ile birlikte ise, kanatın serbest yüzeyde oluşturduğu etki de azalmaktadır

\section{Teșekkür}

Bu çalışma, Çanakkale Onsekiz Mart Universitesi, Bilimsel Araştırma Projeleri Koordinatörlüğü Tarafindan FBA-2019-2984 proje numarası ile desteklenmiştir

\section{Kaynakça}

Abbott, I. H. and Von Doenhoff, (1959). A. E.: Theory of Wing Sections, Dover Publications, New York

Ali, A., Karim, M. (2013). Numerical Study Of Free Surface Effect On The Flow Around Shallowly Submerged Hydrofoils. Proceedings of MARTEC 2010 The International Conference on Marine Technology, 11-12 December 2010, BUET, Dhaka, Bangladesh

Hoque, A.,Karim, M., Rahman, A.,( 2017). Simulation of Water Wave Generated by Shallowly Submerged Asymmetric Hydrofoil, Procedia Engineering, Volume 194, pp 38-43

Huang, L., Huang, P. G., LeBeau, R. P. and Hauser, T. (2004) Numerical Study of Blowing and Suction Control Mechanism on NACA0012 Airfoil, Journal of Aircraft, vol.41 (5)

Bakirci, M. (2020). Kama Şekilli Kanat Üzerindeki Süpersonik Akışı Çözmek için Sayısal Bir Algoritma. European Journal of Science and Technology, (18), pp. 934-942. doi: 10.31590/ejosat.706738. https://dergipark.org.tr/tr/pub/ejosat/issue/52599/706738 
Bal, S., (1999). A potential based panel method for 2-D hydrofoils, Ocean Engineering, Vol. 26, pp. 343-361.

Bal, S., Kinnas, S. A. and Lee, Hee.(2001). Numerical Analysis of 2-D and 3-D Cavitating Hydrofoils Under a Free Surface, Journal of Ship Research, Vol. 45, No:1, pp. 34-49.

Bal, S., (2007). High-speed submerged and surface piercing cavitating hydrofoils, including tandem case, Ocean Engineering, Volume 34, Issues 14-15, Pages 1935-1946

Bal, S., (2011). The effect of finite depth on 2D and 3D cavitating hydrofoils, J Mar Sci Technology, Vol. 16, No: 2, pp.129-142.

Chen, S.L., Yang, S., \& Ma, Q. (2011). An Experimental Study on Hydrodynamic Characteristics of Gliding-Hydrofoil Craft, Journal of Marine Science and Technology, Vol. 19, No. 1, pp. 89-96

Çakıcı, F. ve Kınacı, Ö.K. (2012). Yüksek Froude Sayılarında Çalışan Hidrofoiller Üzerinde Serbest Su Yüzeyi Etkisi, Gemi Inşaatı ve Deniz Teknolojisi Teknik Kongresi 2012 Bildiriler Kitabl, 13-14 Aralık 2012, TMMOB, Gemi Mühendisleri Odas1, İstanbul 183-192.

Drela, M., (1989) XFOIL: An Analysis and Design System for Low Reynolds Number Airfoils, Low Reynolds Number Aerodynamics, Notre Dame, Indiana, June 5-7.

Duncan, J. H., (1983). The breaking and non-breaking wave resistance of a two-dimensional hydrofoil, J. Fluid Mech., Vol. 126, pp. 507-520.

Eleni, D. C., Athanasios, T. I. and Dionissios, P. M.,(2012). Evaluation of turbulence models for the simulation of the flow over a National Advisory Committee for Aeronautics (NACA 0012) airfoil, Journal of Mechanical Engineering Research, Vol. 4, No:3, pp. 100-111.

Ganesh Ram, R. K., Cooper, Y. N., Bhatia, V., Karthikeyan, R., \& Periasamy, C. (2014). Design Optimization and Analysis of NACA 0012 Airfoil Using Computational Fluid Dynamics and Genetic Algorithm. Applied Mechanics and Materials, 664, 111-116. https://doi.org/10.4028/www.scientific.net/amm.664.111

Ghassemi, H., Iranmanesh, M. and Ardeshir, A.,(2010). Simulation of Free Surface Wave Pattern Due To The Moving Bodies, Iranian Journal of Science \& Technology, Transaction B: Engineering, Vol. 34, pp. 117-134.

Karaalioğlu, M , Bal, Ş . (2015). Numerical Investigation Cavitation Buckets for Hydrofoil Parametrically. Turkish Journal of Maritime and Marine Sciences , 1 (2) , 89-101. https://dergipark.org.tr/tr/pub/trjmms/issue/40138/477489

Karaalioğlu, M , Bal, Ş . (2017). Some Remarks on the Three Dimensionality of Hydrofoil Cavitation. Turkish Journal of Maritime and Marine Sciences , 3 (2) , 113-120 https://dergipark.org.tr/tr/pub/trjmms/issue/40149/477568

Karim, Md. M. and Ahammed, M. S., (2012). Numerical study of periodic cavitating flow around NACA 0012 hydrofoil. Ocean Engineering, Vol. 55, pp. 81-87.

Karim, Md. M., Prasad, B. and Rahman, N.,(2014). Numerical simulation of free surface water wave for the flow around NACA 0015 hydrofoil using the volume of fluid (VOF) method, Ocean Engineering, Vol. 78, pp. 89-94.

Katsikadelis, J. T. (2002).Boundary Elements: Theory and Applications, Elsevier, New York,

Körpe, D. S., Kanat, Ö. Ö. and Oktay, T. (2019). Başlangıç y plus Değerinin Etkileri: $\gamma$-Re $\theta$ SST Türbülans Modeli Kullanılarak 3D NACA 4412 Kanadının Sayısal Analizi. European Journal of Science and Technology, (17), pp.
692-702. doi:

10.31590/ejosat.631135 https://dergipark.org.tr/tr/pub/ejosat/issue/48495/631135

Lee, T. M., Park, I. R., Chun, H. H. and Lee, S. J., (2000). Effect of free surface and strut on fins attached to a strut, Ocean Engineering, Vol. 28, pp. 159-177.

Morgado, J., Vizinho, R., Silvestre, M.A.R., Páscoa, J.C. (2016) XFOIL vs CFD performance predictions for high lift low Reynolds number airfoils, Aerospace Science and Technology, Volume 52, , pp 207-214,

Newman, J. N.,(1977). Marine Hydrodynamics. MIT Press, Cambridge,

Nguyen, D.H. and Lee, S. (2018) Investigation on the Accuracy of the TNO Model Using RANS CFD and XFOIL Inputs for Airfoil Trailing Edge Noise Predictions, AIAA/CEAS Aeroacoustics Conference June 25-29, 2018, Atlanta, Georgia

Ni, Z., Dhanak, M., Su, T.C.,(2019). Performance of a slotted hydrofoil operating close to a free surface over a range of angles of attack, Ocean Engineering, vol 188, pp. 106296

Oktay, T. and Kanat, Ö. Ö. (2019). NACA 4412 Kanad 1 Üzerinde Bir Emme Kanalı Tasarlanmasının Aerodinamik Etkileri. European Journal of Science and Technology, (17), pp. 1001-1007. doi: 10.31590/ejosat.651523. https://dergipark.org.tr/tr/pub/ejosat/issue/48495/651523

Ömer Kemal Kinaci, (2015). A Numerical Parametric Study on Hydrofoil Interaction in Tandem, Int. J. Nav. Archit. Ocean Eng. 7:25-40 http://dx.doi.org/10.1515/ijnaoe-2015-0003

Raj,J. (2017). CFD analysis of flow characteristics of NACA0012 airfoil using SU2, Journal of Mechanical and Aeronautical Engineering Research Volume 1 (3), p. 25-28

Sharma, S. and Clement, S. (2014) CFD Simulation of the Flow Characteristics of NACA 0012, NACA 6409, and DHMTU Airfoils in Ground Effect, ASME Fluids Engineering Division Summer Meeting August 3-7, 2014 Chicago, Illinois, USA

Tarafder, Md. S. and Suzuki, K., (2007). Computation of wavemaking resistance of a catamaran in deep water using a potential-based panel method, Ocean Engineering, Vol. 34, pp. 1892-1900.

Tarafder, Md. S., Khalil, G. Md. and Islam, R. M., (2009). Analysis of potential flow around two-dimensional hydrofoil by source based lower and higher order panel methods, The Institution of Engineers Malaysia, Vol. 71, No:2, pp. 13-21.

Tarafder, M. S., Saha, K. G. and Mehedi, T. S.(2010). Analysis of potential flow around three-dimensional hydrofoils by combined source and dipole based panel methods, Journal of Marine Science and Technology, Vol. 18, No: 3, pp. 376384.

Uslu, Y. and Bal, S., (2008). Numerical Prediction of Wave Drag of 2-D and 3-D Bodies under or on a Free Surface, Turkish J. Eng. Env. Sci., Vol. 32, pp. 177-188.

Wehausen, J.V. and Laitone, E. V.,( 1960). Surface waves, Handbuch der Physih,

Wu, P. C. and Chen, J. H.( 2016). Numerical study on cavitating flow due to a hydrofoil near a free surface, Journal of Ocean Engineering and Science, Volume 1 (3), pp. 238-245. 